\title{
Effects of the Fiber Diameter on Mechanic Properties in Polymethyl-Methacrylate Composites Reinforced with Goose Feather Fiber
}

\author{
Kenan Büyükkaya \\ Gazipaşa Campus, Technical Sciences Vocational High School, Giresun University, Giresun, Turkey \\ Email: Kenan.buyukkaya@giresun.edu.tr
}

How to cite this paper: Büyükkaya, $\mathrm{K}$. (2017) Effects of the Fiber Diameter on Mechanic Properties in Polymethyl-Methacrylate Composites Reinforced with Goose Feather Fiber. Materials Sciences and Applications, 8, 811-827.

https://doi.org/10.4236/msa.2017.811059

Received: June 7, 2017

Accepted: October 24, 2017

Published: October 27, 2017

Copyright $\odot 2017$ by author and Scientific Research Publishing Inc. This work is licensed under the Creative Commons Attribution International License (CC BY 4.0).

http://creativecommons.org/licenses/by/4.0/

(c) (i) Open Access

\begin{abstract}
The polymethyl-methacrylate (PMMA)-based composites were prepared using goose feather fibers at different diameters. The fibers, which were washed and dried, cut through the shaft, and their sizes were shrunk to short fiber form. Then the obtained short fibers were added into acryl matrix in portions of $2 \%, 4 \%, 6 \%$, and $8 \%$ in volume. The mixture containing goose feather fiber was shaped via free casting method, and the goose feather fiber/PMMA composites were obtained. The samples, which were processed in accordance with the standards of test to be implemented after the thermal curing process, were characterized in terms of the mechanical properties after being evaluated by using three-point flexure test and impact test. For the goose feather-added composites, a significant increase was observed in rupture resistance, flexural strength, and flexure module. The flexure test curves of composites clearly revealed the slow and stable crack enlargement. Micro mechanisms of toughening and rupture processes were observed under the light of microstructure of rupture surfaces. The results of present study showed that the goose feather can be used as an important reinforcing material for bio-composites.
\end{abstract}

\section{Keywords}

Composite, Mechanical Properties, Goose Feather Fiber, PMMA, Fiber Diameter

\section{Introduction}

Because of various disadvantages of artificial fibers, the interest at developing composites based on fibers obtained from herbal sources increased. When com- 
pared to artificial fibers, these organic fibers, which are environment-friendly, have lower intensity, and it is relatively easier to obtain them. Thanks to their specific properties (strength/weight), the vegetable-based fibers have superior properties when compared to artificial fibers [1] [2].

At least one of the components of these materials, which are called bio-composites, is of biological origin. From the aspect of fibers, the bio-composite materials typically consist of vegetable-origin fibers such as ketene, bamboo, cannabis, sisal, and etc. [3]-[10] or animal-origin fibers such as various feathers [11] [12] [13] [14].

Although there are many studies carried out using cellulose-origin organic fibers (such as flax, jute, sisal, and etc.) obtained from renewable natural sources, there are limited number of studies on the composites made of feathers, one of the protein fibers obtained from agricultural sources. From this aspect, the number of studies carried out using goose feather remained limited due to various reasons. The limited number studies carried out encompass the use of goose feather, their import and export throughout the world, and the productivity of goose feathers [15] [16] [17]. Moreover, some of the studies on this subject are related with the heat transfer of goose feather and its use in textile industry. In their studies, Süpüren et al. [18] and also Gao et al. [19] revealed the structure of goose feather and reported that the special fibers that goose feathers have provided them with high heat-retaining capacity and a lightweight character.

Although there are studies, which were carried out using composites made of chicken feather but still capable of limitedly explaining the mechanical and thermal properties [11] [20] [21] [22], in literature, there is no study carried out using goose feathers and examining the mechanical properties of composites.

In present study, at ambient temperature, it was aimed to investigate the mechanical properties of composites with PMMA matrix composed using goose fiber as reinforcing material. For this purpose, by adding $2 \%$ to $8 \%$ goose feather obtained from breast and wing regions of gooses, 8 different types of composites were obtained, and the dynamic and mechanical analyses of manufactured composites were performed. It was aimed to explain the relationship between inner structure and mechanical properties by examining the ruptured surfaces.

Moreover, the socioeconomic objectives of present study are to eliminate the environmental risks by making use of goose feathers and to economically utilize those materials.

\section{Experimental Procedure}

\subsection{Preparing Samples}

The goose fibers were obtained from the gooses raised in Ardahan province of northern side of Eastern Anatolia region. The goose feathers were washed with alkaline solution $(\mathrm{NaOH})$ then rinsed, and then the breast and wing feathers were separately grouped. In literature, it was reported that the diameters of feathers that are close to the skin are small but they have limited strength [23] 
[24]. In parallel with that, in order to allow the mechanical properties of fibers to be similar to each other, the fibers at both ends of the fibers were cut and removed. By slicing the feathers through the rachis, the breast and wing feathers with similar diameters were obtained. 50 barbs randomly selected from breast and wing regions were characterized in terms of thickness.

In previous studies on mechanical and physical properties of chicken feather, it was reported that the approximate diameter and length of chicken feathers vary between $5-50 \mu \mathrm{m}$ and $1-35 \mathrm{~mm}$, respectively, moreover the mean density was reported to be $0.8 \mathrm{~g} / \mathrm{cm}^{3}$ [25] [26]. The findings obtained from the study carried out using goose feathers are presented in Table 1 , and the values presented corroborate with the values reported in studies, which were carried out using chicken feathers, in literature.

The matrix materials used in preparing the goose fiber/polymethyl-methacrylate composites were procured from Turkey Distributor of Otto Bock (Germany). In order to harden the polymethyl-methacrylate matrix material used, peroxide-based chemical material was obtained from the same company. In the present study, the mechanical properties of composite were revealed at room temperature. For this reason, some of the standard features of PMMA, which have been reported in previous studies, are presented in Table 2 [27] [28].

In order to obtain experimental sample from goose feather/polymethyl-methacrylate composites, the casting molds were prepared using PTFE material. After cutting the goose fibers in $2 \mathrm{~mm}$ length, $2 \%$ peroxide hardener was added into the polymethyl-methacrylate matrix material, and the mixture was poured

Table 1. Physical and mechanical properties of goose fibers.

\begin{tabular}{cc}
\hline Physical and mechanical properties of goose fibers & Average Values \\
\hline Thickness $(\mu \mathrm{m})$ & $5-56$ \\
Strength $(\mathrm{MPa})$ & $41-130$ \\
Young Mod. $(\mathrm{GPa})$ & $2.5-3$ \\
Elong. at Br. $(\%)$ & $1.5-6$ \\
Density $\left(\mathrm{gr} / \mathrm{cm}^{3}\right)$ & 0.8 \\
\hline
\end{tabular}

Table 2. Mechanical properties of standard PMMA.

\begin{tabular}{cc}
\hline Physical and mechanical properties of standard PMMA & Average Values \\
\hline Elongation at Break (\%) & $0.5-5$ \\
Hardness-Rockwell $(\mathrm{M})$ & 93 \\
Impact strength $\left(\mathrm{kJ} / \mathrm{m}^{2}\right)$ & 11 \\
Poisson ratio & $0.35-40$ \\
Elasticity module $(\mathrm{MPa})$ & 3300 \\
Tensile strength $(\mathrm{MPa})$ & $60-70$ \\
Fracture toughness $\left(\mathrm{MN} / \mathrm{m}^{3 / 2}\right)$ & $0.7-1.7$ \\
\hline
\end{tabular}


into the molds. Following the casting procedure, the mold was closed and $5 \mathrm{MPa}$ pressure was applied. After the completion of reaction, the samples taken out from molds were kept in an oven at $80^{\circ} \mathrm{C}$ for 24 hours as final cure.

The samples were processed in automatized looms according to the standards (Figure 1). The standard notches with $0.2 \mathrm{a} / \mathrm{w}$ ratio were created on the fracture toughness samples.

\subsection{Characterization}

Scanning electron microscope images were obtained using JSM-5910 following the gold-plating procedure. SEM images were assessed via the detailed evaluation of rupture surfaces of goose fiber/PMMA composites.

\subsection{Point Bending and Impact Strength Tests}

The rectangular sticks $(70 \times 12 \times 6$ in dimension) were tested using 3-Point Bending Test with $48 \mathrm{~mm}$ bracket interval in order to calculate the flexural strength $(\sigma \mathrm{F})$, elasticity module $\left(\mathrm{E}_{\mathrm{f}}\right)$, and fracture toughness $\left(\mathrm{K}_{\mathrm{IC}}\right)$. Clip gauge (SHIMADZU P701805) was utilized in order to measure the gap at the tip of crack. The clip gauge was $3 \mathrm{~mm}$ in length, $5 \mathrm{~mm}$ in range of motion, and Max 10 $\mathrm{MHz}$ in frequency. The samples having $0,0.3 \mathrm{a} / \mathrm{w}$ (length of notch/width of sample) ratio were used for $K_{I C}$ measurement. The 3-Point Bending Test was performed at $1.0 \mathrm{~mm} / \mathrm{min}$. rate of motion by using a universal testing device (SHIMADZU EHF-LV020K2-020) (Figure 2). The $K_{I C}$ values were calculated according to the formulas below [29]:

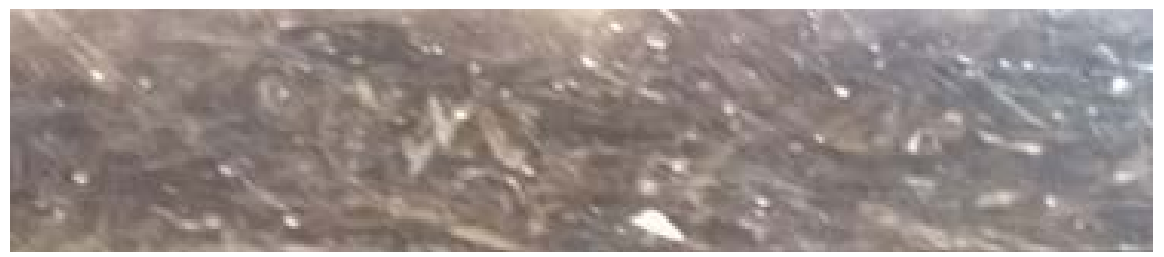

Figure 1. 3-point bending test sample.

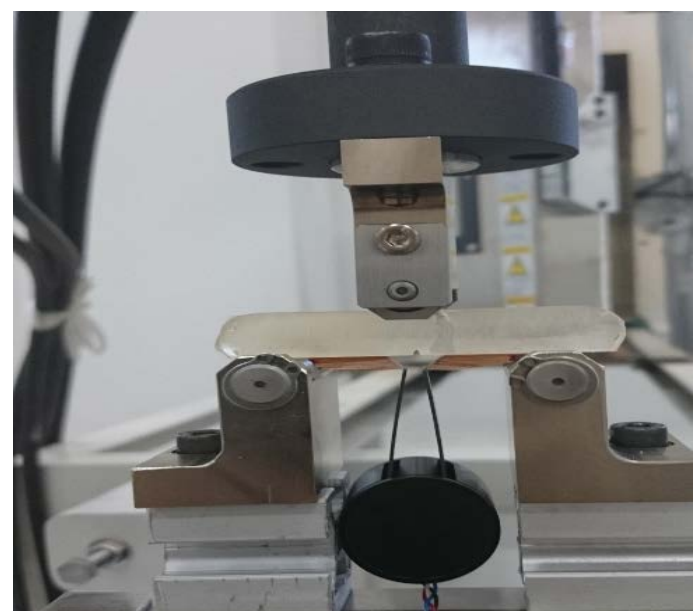

Figure 2. Flexure and rupture test setup. 


$$
\begin{gathered}
J_{I C}=\frac{2\left(A_{t}-A_{u}\right)}{b(W-a)} \\
K_{I C}^{2}=\left(\frac{E}{1-v^{2}}\right) J_{I C}
\end{gathered}
$$

where, $E$ is the flexure module, and $v$ represents the Poisson ratio.

Charpy impact test was performed according to the procedures specified in ASTM D256-78-B.

For every percentage, 5 test samples were used, and the mean values of absorbed energy were calculated.

In order to interpret the rupture energy, the rectangular stick samples without any notch were tested using Zwick B5113Charpy impact test device having 40 $\mathrm{mm}$ of bearing distance and $2.0 \mathrm{~J}$ pendulum hammer, and the impact strength $\left(\mathrm{kJ} / \mathrm{m}^{2}\right)$ was calculated.

\section{Results}

\subsection{Effects of Morphological Properties and Percentage of Fiber on Flexure Tension and Module}

The flexural properties of pure and goose-fiber-added polymethyl-methacrylate composites were evaluated using 3-point flexure test, and the diagrams are shown in Figure 3 and Figure 4. When compared to pure PMMA, there are some remarkable differences. Despite the low fiber concentration, the remarkable increases in flexure tension $\left(\sigma_{\mathrm{fm}}\right)$, flexure module $\left(E_{f}\right)$, and rupture toughness $\left(\mathrm{K}_{\mathrm{IC}}\right)$ were obtained when goose fiber was added. When compared to pure matrix, the increases in flexure tension were found to be $3.7 \%, 16 \%, 26 \%$, and $39 \%$ in composites added with $2 \%-8 \%$ goose fibers. At $2 \%$ additive level, the

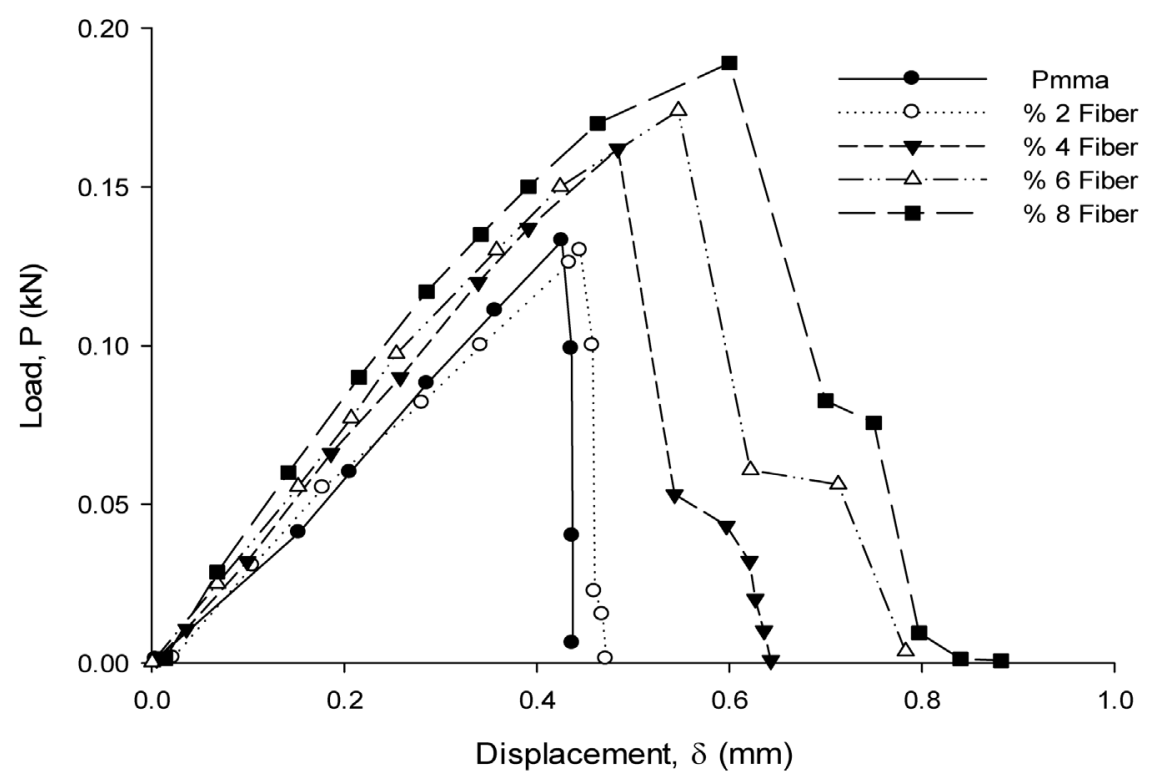

Figure 3. Load-Elongation diagram of PMMA and samples having $0.2 \mathrm{~mm}$ notch and added with $2 \%-8 \%$ fine fiber. 


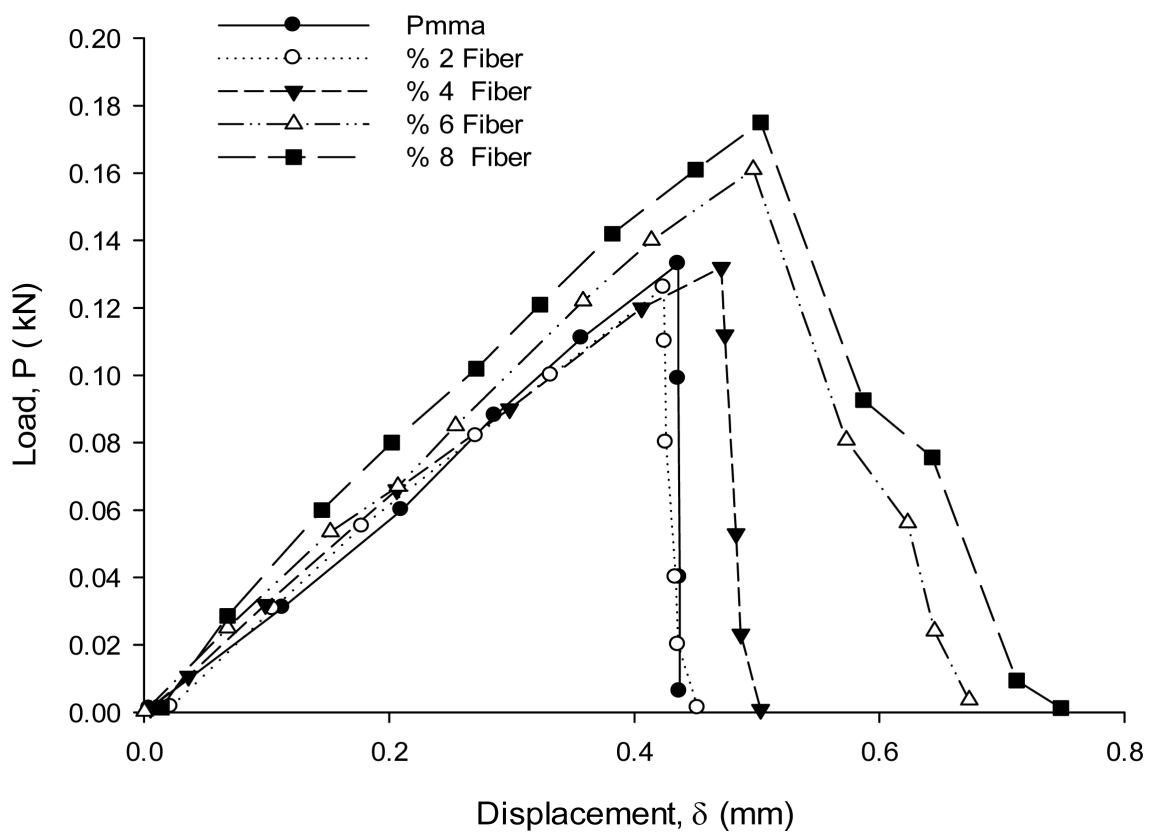

Figure 4. Load-Displacement Diagram of PMMA and 2\% - 8\% thick-fiber-added samples with 0.2 notch.

behavior of matrix was seen to be dominant but, as the percentage increased, an increase trend was observed in flexure tension levels. In elasticity module, the levels of increase observed were found to be $2 \%, 12 \%, 22 \%$, and $36 \%$, respectively (Figure 5). Similarly, the tension levels of composites added with thick fiber were found to be $5.2 \%,-1 \%, 18 \%$, and $27 \%$, respectively. When compared to fine fibers, the tension decreased in thick fibers to $4 \%$ level and then the increase stated at the level of $6 \%$. This result is believed to be closely related with the geometry of fiber. The increases observed in elasticity module were $4 \%, 10 \%$, $16 \%$, and $26 \%$, respectively (Figure 6). While the reinforced composite material showed stable and slow crack enlargement during the test, the PMMA samples showed faster crack enlargement (Figure 3 ). This finding clearly verifies that the composites added with goose fiber absorbed higher level energy while rupturing started from $4 \%$ concentration for fine fibers and $6 \%$ concentration for thick fibers.

Within certain limitations, the stress properties of composites were significantly improved by adding fibers into the polymer matrix and increasing the matrix strength and rigidity [30] [31]. The concentration of these reinforcement materials also affects the mechanical properties of composite. For this reason, the effect of fiber content on the mechanical properties of composites has been accepted to be an important and interesting research subject by many researchers [32].

The characteristics of matrix and fibers and the harmony between them are very important in improving the mechanical properties of composites. The surface connection between matrix and fiber is the most important factor in improving the properties. Besides that, the harmony of some of the morphological 




Figure 5. Bending stress of composite reinforced with fine fiber and the change of module by the weight ratio.



Figure 6. Bending stress of composite reinforced with thick fiber and the change of module by the weight ratio.

properties of fiber (fiber diameter, critical fiber length, cross-section shape of fiber) [33] were reported to positively contribute to improving these properties. In present study, it was confirmed that the physical properties of goose feather used as reinforcement material significantly affected the mechanical properties of composite. Increase in diameter of fiber caused the decreases in both load values and dislocation levels. Therefore, the increase in fiber diameter led to partial decreases in stress and bending stress levels. 
Besides the morphological properties of goose fiber, the chemical structure also plays important role in improving those properties. Chemical structure of fibers is determined by various amino acids within the keratin. The structure constructed by those amino acids plays important role in various properties of feathers such as hydrophobic behavior, hydrogen bonds, mechanical properties, dipole effects, and cysteine-based S-S bonds. Among those structures, the cross-links have improving effect on the mechanical properties of keratin fibers [34] [35].

In previous studies, it was revealed that the linear behavior of keratin fibers under stress originates from the changes in bond angles and bond gaps [36], but the secondary structure within the spiral structure of micro-fibrils in this reason are not affected. Due to the constant increase in stress, the spiral structure opens as a result of rearrangement in hydrogen bonds related with the keratin compounds. This event causes a change in secondary structure called $\alpha-\beta$ transition in wool and hair [37]. Around the defected area, the fiber loses its mechanical properties, and finally the hydrogen bonds break and the disulfide linkages break into pieces. As a result, the natural structure of natural structure of protein deteriorates.

\subsection{The Effects of Fiber, Morphological Properties, and Concentration on Fracture Toughness}

In order to better calculate the fracture toughness, the J-Integral method that is more sensitive to the energy absorption was used in present study.

J-Integral method is a method of calculating the rate of strain energy release during testing a material or the energy corresponding to a unit area during the formation of crack. This method has been theoretically developed by Cherepanov in 1967 [26]. The objective in this method is to determine the energy required for creating unit area of crack. For this reason, it is required to determine the energy that is absorbed by the notched and non-notched samples until the fracture. For this purpose, both of the samples were exposed to 3-Point Bending Test, and then the areas under the obtained load-displacement diagram were determined (Figure 7). The differences between the areas under curve revealed the energy consumed for the formation of crack surface.

The Load-Displacement diagram of notched and non-notched samples is presented in Figure 7. The areas under both curves were determined using Matlabsoftware. By putting the values in equation, the J-Integral values (energy values) were calculated. The obtained J-Integral $\left(\mathrm{J}_{\mathrm{IC}}\right)$ values were used for calculating $\mathrm{K}_{\mathrm{IC}}$ values.

The increases in fracture toughness were found to be $-3 \%, 25 \%, 34 \%$, and $45 \%$ in composites reinforced with fine fibers and $-4 \%,-1 \%, 24 \%$ and $35 \%$ in composites added with thick fiber (Figure 8).

The increase in fracture strength might be attributed to the mechanisms such as debonding, fiber bridging, fiber pullout, and fiber breaking during the fracture in fiber-matrix interface. As mentioned before, the increase in these 


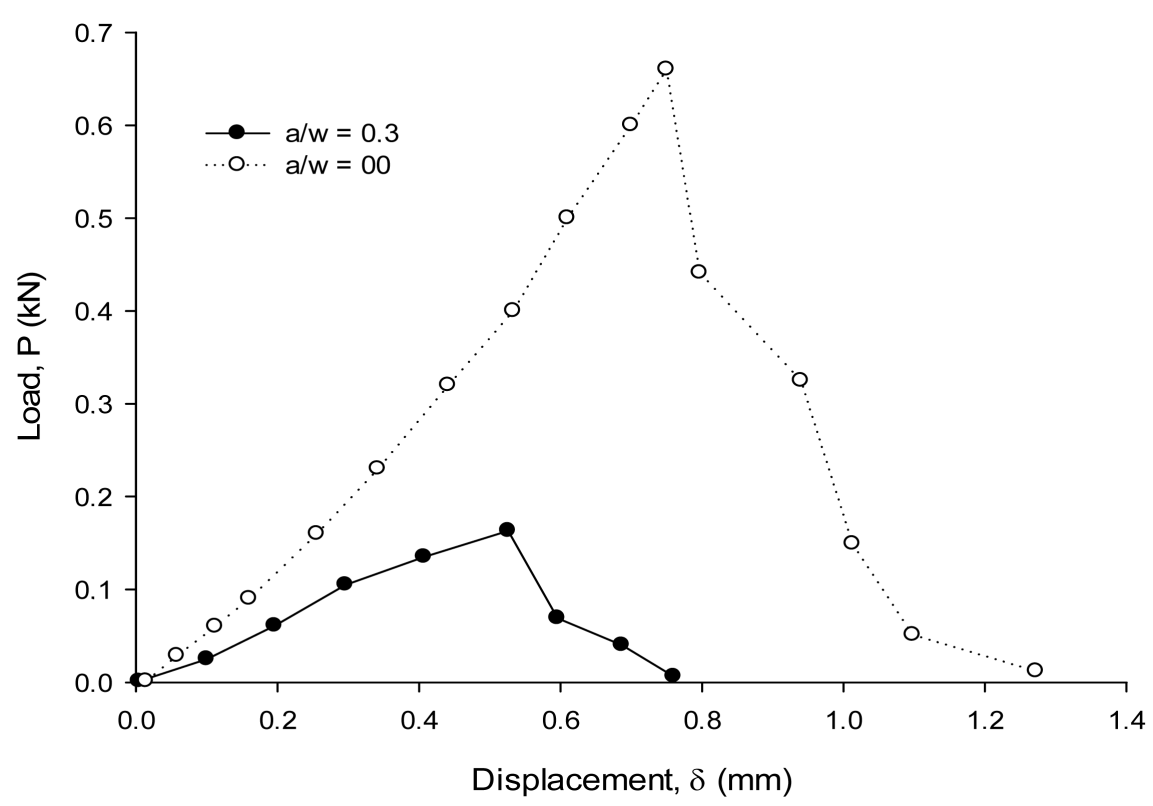

Figure 7. Notched and non-notched load-displacement diagram of composite reinforced with $8 \%$ fine fiber.

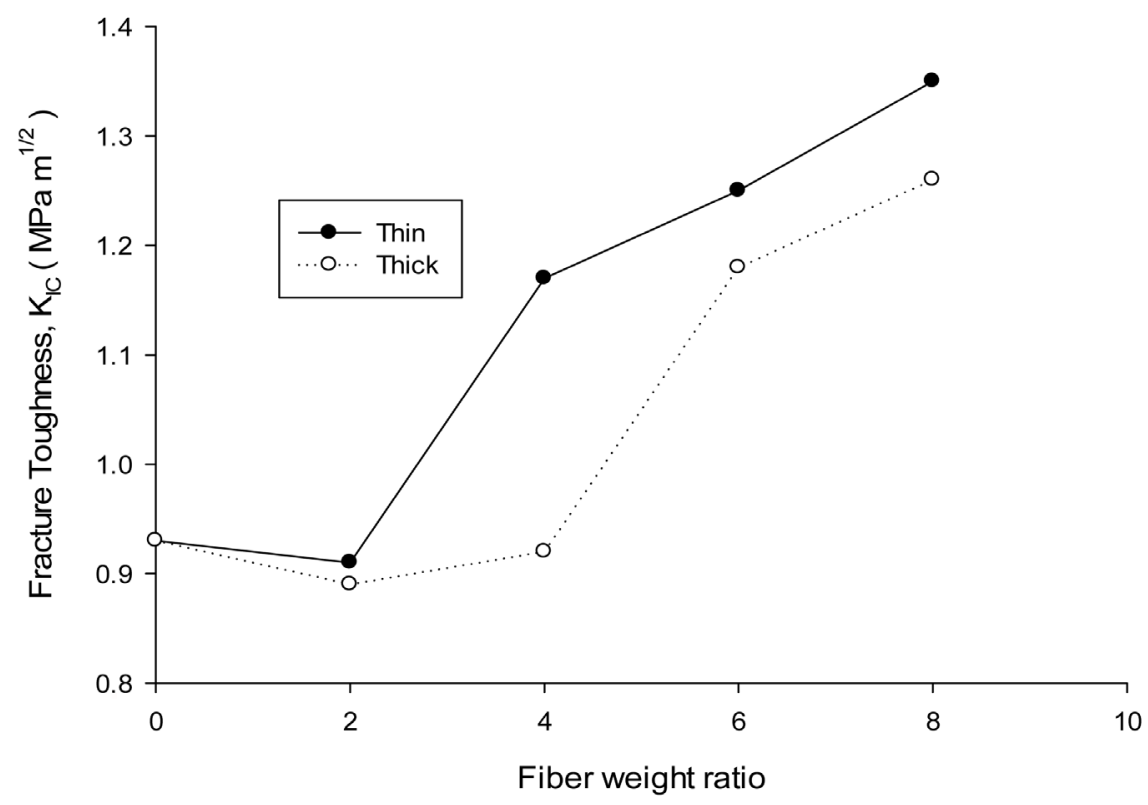

Figure 8. Change of fracture toughness by volumetric portion of fiber.

properties depends on the volume fraction, and fiber-matrix harmony [38]. In the micrographs, it can be seen that the increase in fracture resistance originated from the energy-absorbing mechanisms such as fiber decomposition and fiber fracture.

\subsection{The Effects of Fiber, Its Morphological Properties, and Concentration on Impact Resistance}

The presence of goose fiber influenced the impact resistance of PMMA matrix at 
various levels depending on the thickness of fiber. When compared to pure PMMA, the impact strength of composites with $2 \%-8 \%$ fine fiber reinforcement changed by $-13 \%,-5 \%, 9 \%$, and $20 \%$. The changes observed in composites reinforced with thick fiber were found to be $-20 \%,-12 \%,-6 \%$, and $10 \%$ (Figure 9).

The impact resistance performances of 2 fibers significantly differ from each other. At this point, it is necessary to focus on two factors. First one is the increase in spaces within the fiber due to increasing fiber diameter and consequently significant level of decreases occurred in impact resistance of composites with $2 \%-6 \%$ reinforcement were observed. Second one is the consequences of the geometry of thick fibers. As seen in Figure 10(g), the cross-section of thick fiber has a shape geometry that is very different from normal one. Depending on the shape geometry that is very different from normal, the impact strength of composites with $2 \%$ reinforcement significantly decreases due to the worsened brittle breaking tendency of matrix by the fiber. It decreasingly continues towards the composites with $6 \%$ reinforcement, and slight increase is seen in composites with $8 \%$ reinforcement.

$13 \%$ decrease occurred because the factors originating from the pour and shape geometry of composites reinforced with fine fiber are lower than they are for thick fibers. The increase in reinforcement concentration decreased the rate of decline and finally $20 \%$ increase was observed. Including the composites with $6 \%$ reinforcement, the brittle character of breaking changed and consequently an increase was observed in impact strength.

The increase in breaking energy and fracture toughness of fibers was confirmed in some of the studies on keratin fibers [39]. This finding verifies that the

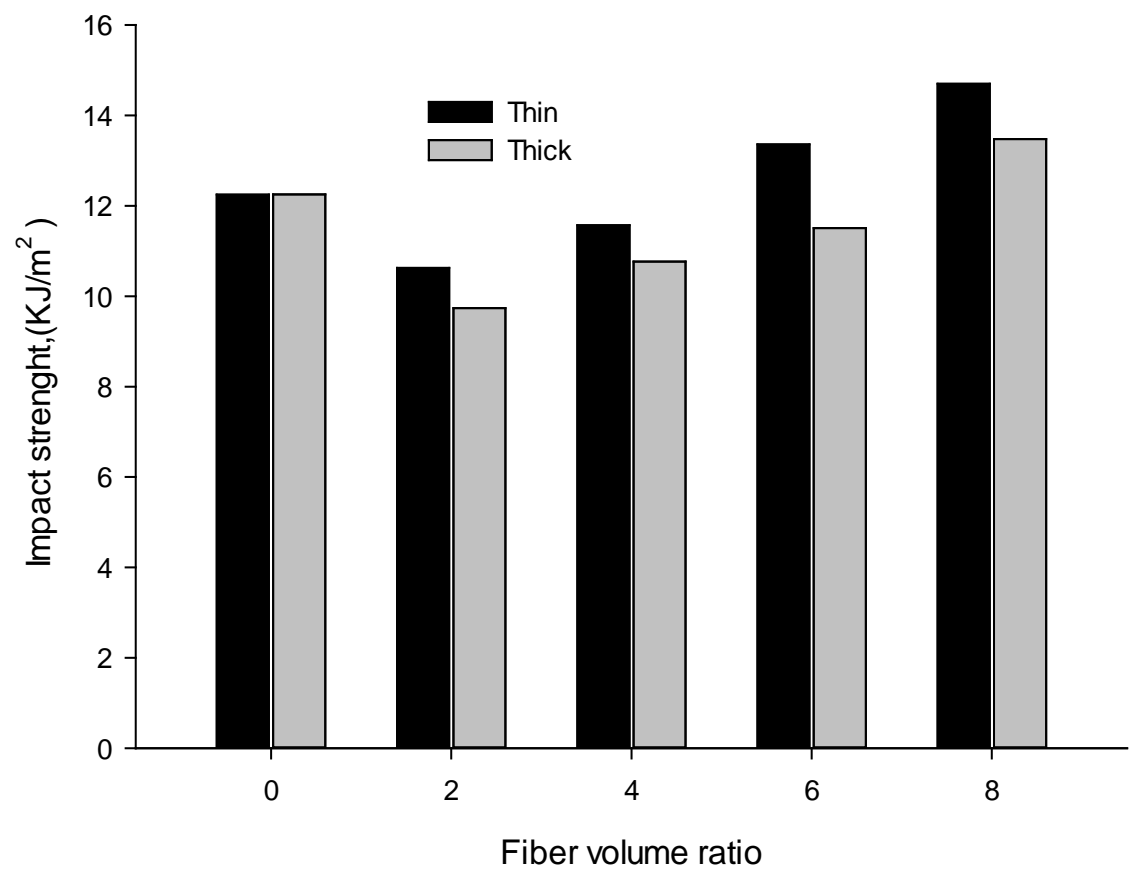

Figure 9. Change of impact resistance by volumetric portion of fiber. 


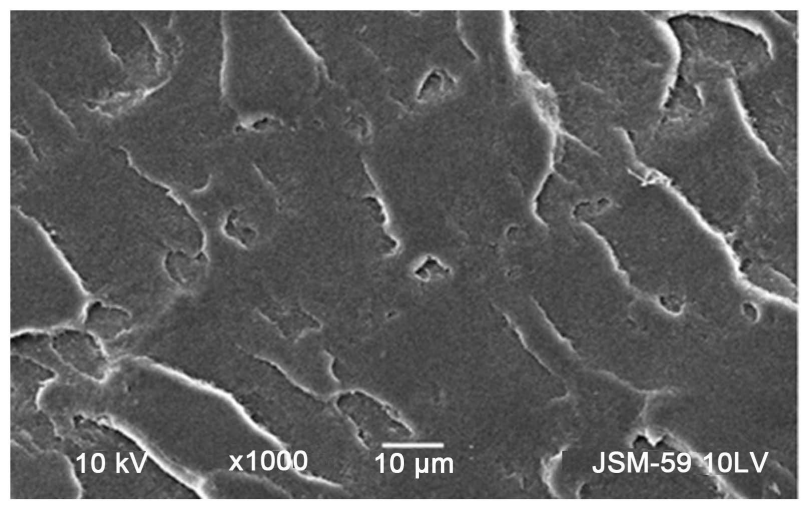

(a)

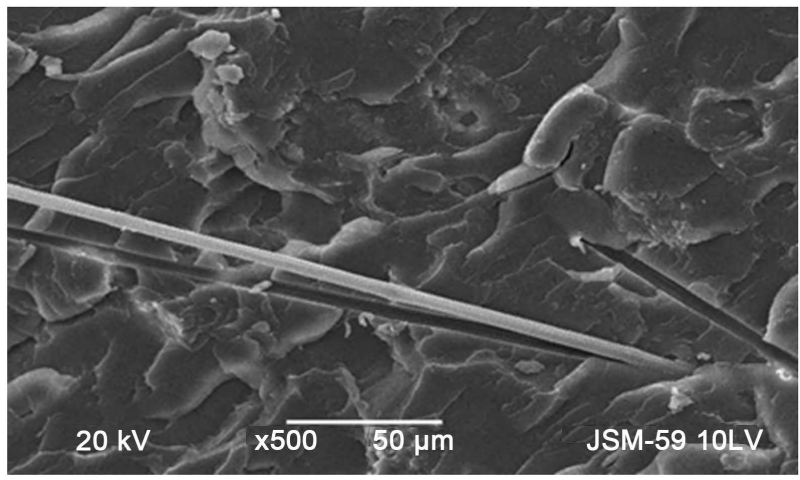

(b)

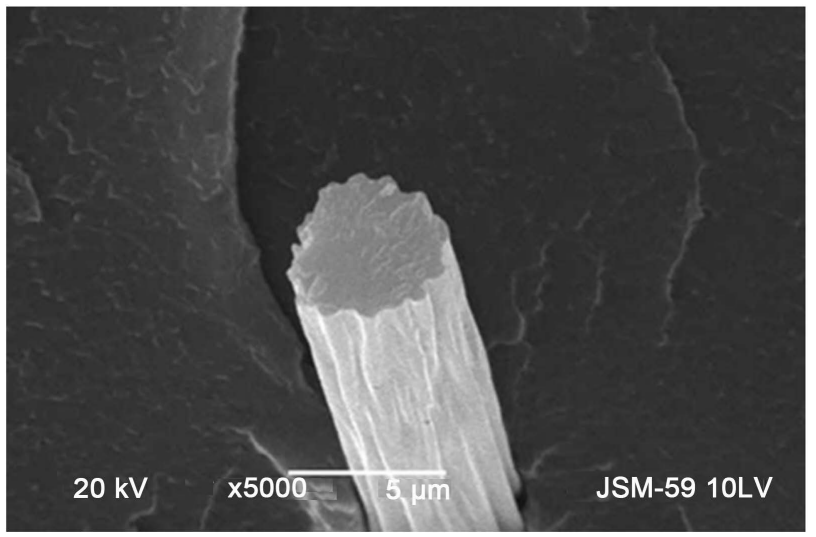

(c)

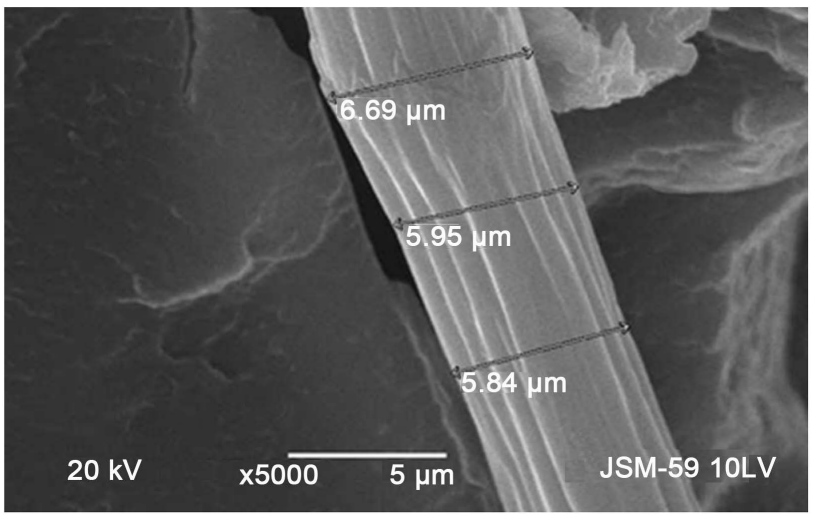

(d) 


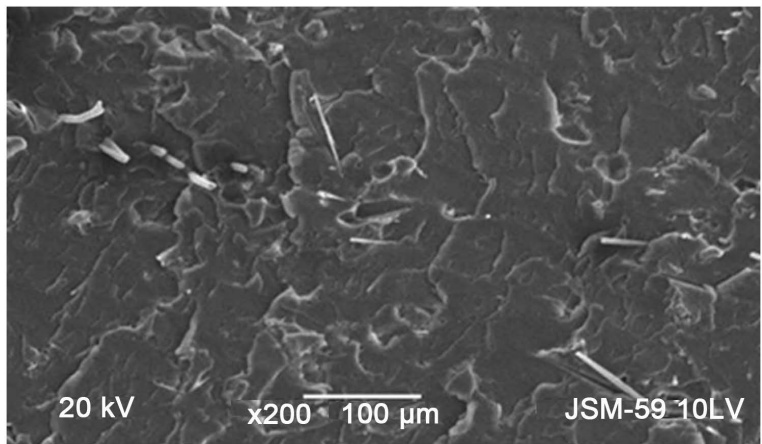

(e)

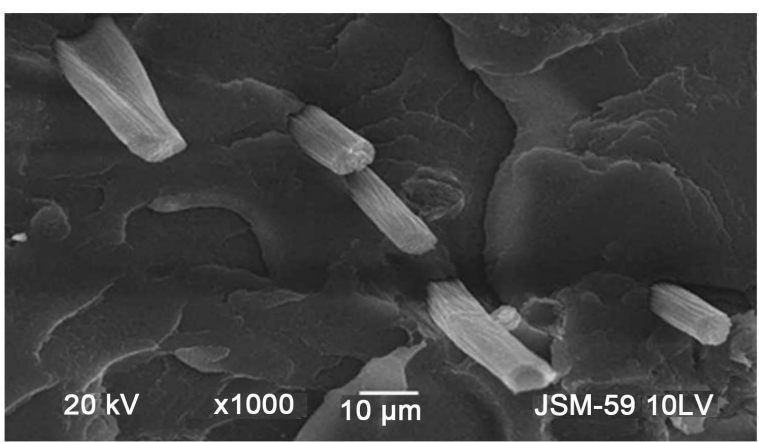

(f)

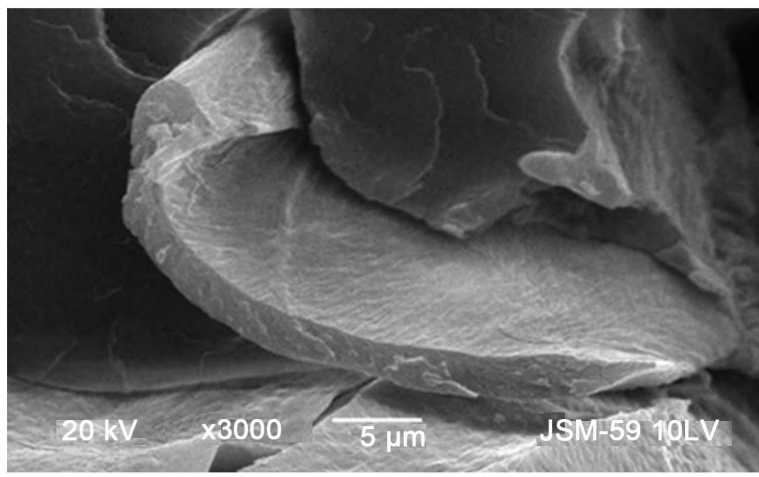

(g)



(h)

Figure 10. (a) Micro image of fracture surface of pure PMMA; (b) Micro image of composite reinforced with fine fiber; (c) Micro image of damaged single fine fiber; (d) Micro image of damaged single fine fiber; (e) Micro image of composite reinforced with fine fiber; (f) Micro image of composite reinforced with fine fiber; (g) Micro image of single thick fiber after the test; (h) Micro image of composite reinforced with thick fiber. 
crack propagation observed in micro-imaging occurred via different mechanisms. As stated before, these fracture mechanisms are the mechanisms such as fiber debonding, fiber bridging, fiber pullout, and fiber breakage. Even though the abovementioned mechanisms are effective, the highest efficiency in impact tests was observed in fiber breakage mechanism. In order mechanisms, relatively higher speed prevents the system from having sufficient time for completion (Figure 10(f)). This behavior changes depending on the fiber reinforcement level. If the fiber reinforcement level is low or in cases of fiber fracture or high or low level of fiber strength, the fracture that was efficient at the beginning of test is replaced by other mechanisms towards the end of test.

\subsection{Morphology}

Post-test fracture surface SEM microphotographs of goose fiber/PMMA composite samples are presented in Figures 10(a)-(h). There are longitudinal grooves on the fine goose fiber. Moreover, when examined in detail, it can be seen that the diameter starts increasing starting from a point and then maximizes (Figure 10(d)). This finding confirms that the cross-section is not the same at all the points. This phenomenon leads the damage to occur mainly in form of fiber fracture, because the matrix doesn't allow the pullout of fibers in parallel with tension in case of unilateral tensioning. Given the cross-section of thick fibers, it can be seen that the tip segment of fibers seems like the tip of a knife. From that point, it starts curl at the same thickness level and the curling increases towards the bottom part. In physical properties of fibers, it is stated that this geometry is not appropriate for the load transfer. This finding clarifies why the mechanical resistance of composites made of thick fibers is lower than that of composites made of fine fibers. Moreover, how this geometry promotes the fracture in impact strength can be clarified with the $1 / 3$ decrease of impact strength when compared to pure material. In diagrams, it can be easily seen that PMMA didn't show remarkable plastic deformation during breakage and it fractured in brittle manner.

\section{Results and Discussion}

The presents study revealed that a composite having better mechanical properties can be successfully developed by reinforcing the PMMA matrix with fine goose fiber as reinforcing material. When compared to PMMA matrix, bending properties of goose fiber-PMMA composites are significantly higher. As well as the bending strength, it is also believed that the gap-surface interaction played significant role. These results suggest that, in terms of mechanical properties, the goose fiber might be an alternative in some of industries when compared to synthetic fibers from the aspect of weight/strength ratio.

Positive damage tolerance of fine goose fiber composites might be related with compact processes of energy loss occurring around the crack tip. In composites, when compared to proper fracture surfaces of PMMA, non-planar pre-micro 
cracks propagate locally in different directions throughout the sample thickness because of the abovementioned fracture surfaces. Despite the low rates, the increase in fracture toughness might be assumed to occur as a result of synchronous and interactive occurrence of micro damage processes such as stable propagation of crack.

The thick fibers significantly increase the rate of critical fiber because of their unsuitable shape. For this reason, especially in applications that are exposed to high loads, the use in low concentrations might cause negative consequences and thus it is believed that it would be better to not use them in such cases.

It was emphasized in this study that the composites, especially those prepared with fine goose fiber, positively affect the mechanical properties. Moreover, considering that the thermal and acoustic properties of goose fiber is very positive, it is clear that using these fibers in constructional applications would significantly contribute to energy efficiency and sound insulation of composites.

Using the composites reinforced with goose fiber instead of certain classical materials that are still in use in construction industry (except for the main carriers) would offer significant saving from the weight since it would decrease the concentration. Thus, the use of composites in constructional applications would enable saving from certain cost elements (transportation, efficiency, and etc.), for which the weight is an important factor.

\section{Conclusion}

Within the scope of utilizing the wastes, it is thought that agricultural fibers might be used in some applications instead of using fossil-based fibers in all of them, and that the environment-friendly and natural materials might be developed if the studies on this subject are provided with more opportunities. Moreover, it should be noted that making use of wastes from the socioeconomic aspect would have positive contributions to the society.

\section{References}

[1] Mohanty, A.K., Misra, M. and Drzal, L.T. (2002) Sustainable Bio-Composites from Renewable Resources: Opportunities and Challenges in the Green Materials World. Journal of Polymers and the Environment, 10, 19-26. https://doi.org/10.1023/A:1021013921916

[2] Bledzki, A.K. and Gassan, J. (1999) Composites Reinforced with Cellulose Based Fibres. Progress in Polymer Science, 24, 221-274. https://doi.org/10.1016/S0079-6700(98)00018-5

[3] Lundquist, L., Marque, B., Hagstrand, P.O., Leterrier, Y. and Månson, J.A. (2003) Novel Pulp Fibre Reinforced Thermoplastic Composites. Composites Science and Technology, 63, 137-152. https://doi.org/10.1016/S0266-3538(02)00192-6

[4] Jana, S.C. and Prieto, A. (2002) On the Development of Natural Fiber Composites of High-Temperature Thermoplastic Polymers. Journal of Applied Polymer Science, 86, 2159-2167. https://doi.org/10.1002/app.11073

[5] Nuñez, A.J., Kenny, J.M., Reboredo, M.M., Aranguren, M.I. and Marcovich, N.E. (2002) Thermal and Dynamic Mechanical Characterization of Polypropylene- 
Woodflour Composites. Polymer Engineering \& Science, 42, 733-742. https://doi.org/10.1002/pen.10985

[6] Schneider, J.P., Myers, G.E., Clemons, C.M. and English, B.W. (1995) Biofibers as Reinforcing Fillers in Thermoplastic Composites. Journal of Vinyl and Additive Technology, 1, 103-108. https://doi.org/10.1002/vnl.730010212.n

[7] Hughes, M., Hill, C. A.S. and Hague, J.R.B. (2002) The Fracture Toughness of Bastfibre Reinforced Polyester Composites Part 1 Evaluation and Analysis. Journal of materials science, 37, 4669-4676. https://doi.org/10.1023/A:1020621020862

[8] Jayaraman, K. (2003) Manufacturing Sisal-Polypropylene Composites with Minimum Fibre Degradation. Composites Science and Technology, 63, 367-374. https://doi.org/10.1016/S0266-3538(02)00217-8

[9] Rana, A.K., Mandal, A. and Bandyopadhyay, S. (2003) Short Jute Fiber Reinforced Polypropylene Composites: Effect of Compatibiliser, Impact Modifier and Fiber Loading. Composites Science and Technology, 63, 801-806. https://doi.org/10.1016/S0266-3538(02)00267-1

[10] Mothé, C.G., Monteiro, D.F.J. and Mothé, M. G. (2016) Dynamic Mechanical and Thermal Behavior Analysis of Composites Based on Polypropylene Recycled with Vegetal Leaves. Materials Sciences and Applications, 7, 349. https://doi.org/10.4236/msa.2016.77031

[11] Winandy, J.E., Muehl, J.H., Glaeser, J.A. and Schmidt, W. (2007) Chicken Feather Fiber as an Additive in MDF Composites. Journal of Natural Fibers, 4, 35-48. https://doi.org/10.1300/J395v04n01_04

[12] Aluigi, A., Vineis, C., Ceria, A. and Tonin, C. (2008) Composite Biomaterials from Fibre Wastes: Characterization of Wool-Cellulose Acetate Blends. Composites Part A: Applied Science and Manufacturing, 39, 126-132.

[13] Fraser, R.D. and MacRae, T.P. (1979) Molecular Structure and Mechanical Properties of Keratins. In: Symposia of the Society for Experimental Biology, Vol. 34, 211-246.

[14] Aluigi, A., Vineis, C., Varesano, A., Mazzuchetti, G., Ferrero, F. and Tonin, C. (2008) Structure and Properties of Keratin/PEO Blend Nanofibres. European Polymer Journal, 44, 2465-2475.

[15] Buckland, R.B. and Guy, G. (2002) Goose Production (No. 154) Food \& Agriculture Org.

[16] Çelik, B. (2007) Muşyöresiyerlikazlarındakesimvekarkasözellikleri. Master's Thesis, Afyon Kocatepe Üniversitesi, SağlıkBilimleriEnstitüsü.

[17] Shalev, B.A. and Pasternak, H. (1999) Genetic-Economic Evaluation of Traits in a Goose Meat Enterprise. British Poultry Science, 40, 221-226. https://doi.org/10.1080/00071669987638

[18] Süpüren Mengüç, G. and Özdil, N. (2014) Özel Hayvansal Lifler. Electronic Journal of Vehicle Technologies, 8.

[19] Gao, J., Yu, W. and Pan, N. (2007) Structures and Properties of the Goose down as a Material for Thermal Insulation. Textile Research Journal, 77, 617-626. https://doi.org/10.1177/0040517507079408

[20] Zhan, M. and Wool, R.P. (2013) Thermal Expansivity of Chicken Feather Fiber Reinforced Epoxy Composites. Journal of Applied Polymer Science, 128, 997-1003. https://doi.org/10.1002/app.38142

[21] Cheng, S., Lau, K.T., Liu, T., Zhao, Y., Lam, P.M. and Yin, Y. (2009) Mechanical and Thermal Properties of Chicken Feather Fiber/PLA Green Composites. Compo- 
sites Part B: Engineering, 40, 650-654.

[22] Ghani, S.A., Tan, S.J. and Yeng, T.S. (2013) Properties of Chicken Feather Fiber-Filled Low-Density Polyethylene Composites: The Effect of Polyethylene Grafted Maleic Anhydride. Polymer-Plastics Technology and Engineering, 52, 495-500. https://doi.org/10.1080/03602559.2012.762018

[23] George, B.R., Evazynajad, A., Bockarie, A., McBride, H., Bunik, T. and Scutti, A. (2004) Keratin Fiber Nonwovens for Erosion Control. In: Natural Fibers, Plastics and Composites, Springer, 67-81. https://doi.org/10.1007/978-1-4419-9050-1_5

[24] Barone, J.R. and Schmidt, W.F. (2005) Polyethylene Reinforced with Keratin Fibers Obtained from Chicken Feathers. Composites Science and Technology, 65, 173-181.

[25] Alonso, R.S., Sanches, R. and Marcicano, J.P.P. (2013) Chicken Feather-Study of Physical Properties of Textile Fibers for Commercial Use. International Journal of Textile and Fashion Technology, 1, 29-38.

[26] Cherepanov, G.P. (1967) The Propagation of Cracks in a Continuous Medium. Journal of Applied Mathematics and Mechanic, 31, 503-512.

[27] Zhang, X., Sun, Z. and Hu, X. (2014) Low Temperature Fracture Toughness of PMMA and Crack-Tip Conditions under Flat-Tipped Cylindrical Indenter. Polymer Testing, 38, 57-63.

[28] Marshall, G.P., Coutts, L.H. and Williams, J.G. (1974) Temperature Effects in the Fracture of PMMA. Journal of Materials Science, 9, 1409-1419. https://doi.org/10.1007/BF00552926

[29] Atkins, A.G. and Mai, Y.W. (1985) Elastic and Plastic Fracture: Metals, Polymers, Ceramics, Composites, Biological Materials. Halsted Press, Ellis Horwood.

[30] Ku, H., Wang, H., Pattarachaiyakoop, N. and Trada, M. (2011) A Review on the Tensile Properties of Natural Fiber Reinforced Polymer Composites. Composites Part B: Engineering, 42, 856-873.

[31] Malkapuram, R., Kumar, V. and Negi, Y.S. (2009) Recent Development in Natural Fiber Reinforced Polypropylene Composites. Journal of Reinforced Plastics and Composites, 28, 1169-1189. https://doi.org/10.1177/0731684407087759

[32] Holbery, J. and Houston, D. (2006) Natural-Fiber-Reinforced Polymer Composites in Automotive Applications. JOM Journal of the Minerals, Metals and Materials Society, 58, 80-86. https://doi.org/10.1007/s11837-006-0234-2

[33] Cameron, G.J., Wess, T.J. and Bonser, R.H.C. (2003) Young's Modulus Varies with Differential Orientation of Keratin in Feathers. Journal of Structural Biology, 143, 118-123.

[34] Martinez-Hernandez, A.L., Velasco-Santos, C., de-Icaza, M. and Castaño, V. (2003) Hierarchical Microstructure in Keratin Biofibers. Microscopy and Microanalysis, 9 , 1282-1283.

[35] Zhan, M. and Wool, R.P. (2011) Mechanical Properties of Chicken Feather Fibers. Polymer Composites, 32, 937-944. https://doi.org/10.1002/pc.21112

[36] Martínez-Hernández, A.L. and Velasco-Santos, C. (2012) Keratin Fibers from Chicken Feathers: Structure and Advances in Polymer Composites. Keratin: Structure, Properties and Applications, 149-211.

[37] Hearle, J.W.S. (2000) A Critical Review of the Structural Mechanics of Wool and Hair Fibres. International Journal of Biological Macromolecules, 27, 123-138.

[38] Low, I.M., Schmidt, P. and Lane, J. (1995) Synthesis and Properties of Cellulose-Fibre/Epoxy Laminates. Journal of Materials Science Letters, 14, 170-172. https://doi.org/10.1007/BF00318245 
[39] Hong, C.K. and Wool, R.P. (2005) Development of a Bio-Based Composite Material from Soybean Oil and Keratin Fibers. Journal of Applied Polymer Science, 95, 1524-1538. https://doi.org/10.1002/app.21044 